Discussion Paper Series No.197

Pollution Havens and Industrial Agglomeration

\author{
Dao-Zhi ZENG Kagawa University \\ Laixun ZHAO Kobe University
}

November 2006

The Discussion Papers are a series of research papers in their draft form, circulated to encourage discussion and comment. Citation and use of such a paper should take account of its provisional character. In some cases, a written consent of the author may be required. 


\title{
Pollution Havens and Industrial Agglomeration
}

\author{
Dao-Zhi Zeng* $\quad$ Laixun Zhao ${ }^{\dagger}$
}

November 13, 2006

\begin{abstract}
Pollution-intensive industries are generally characterized by imperfect competition, increasing returns to scale and large transportation costs. We investigate two countries, $\mathrm{N}$ and $\mathrm{S}$, each with two sectors. Manufacturing generates cross-border pollution which reduces agricultural production. Firms can freely move across country borders, but not workers. First, we show that pollution lowers local income since it reduces agricultural production. This income-reduction effect discourages firms to move to the country with laxer environmental regulations that generate more pollution. Second, our analysis demonstrates that manufacturing agglomeration forces can alleviate the pollution haven effect. And a pollution haven may not arise, if environmental regulation is slightly more stringent in the larger country $\mathrm{N}$ than in the smaller country S. These results are strongly supported by recent empirical findings. In addition, the model predictions call for international cooperation of environmental policies, especially when trade becomes freer.
\end{abstract}

Keywords: Pollution, Industrial Agglomeration, Trade Costs

JEL Classification: Q5, R3

\footnotetext{
*Graduate School of Management, Kagawa University, Saiwai-Cho 2-1, Kagawa 760-8523, Japan. E-mail: zeng@ec.kagawa-u.ac.jp.

${ }^{\dagger}$ Laixun Zhao, Research Institute for Economics and Business, Kobe University, Kobe 657-8501, Japan. E-mail: zhao@rieb.kobe-u.ac.jp.
} 


\section{Introduction}

The so-called "pollution haven" hypothesis ${ }^{1}$ states that pollution-intensive industries will, in response to globalization (e.g. freer trade or capital mobility), tend to move to countries with laxer environmental regulations. ${ }^{2}$ The issue plays important roles in the design of international agreements such as the Kyoto Protocol on greenhouse gas control and the Montreal Protocol on ozone-depleting substances. However, while it is intuitively understandable that polluting firms relocate to countries with lenient environmental regulations, a majority of the empirical findings on the pollution-haven effect are weak and controversial. $^{3}$

A number of studies have attempted to explain for the huge gap between the existing theoretical literature and the empirical findings. For instance, Grossman and Kruger (1993) state that the direction of trade in dirty goods is primarily determined by conventional determinants of comparative advantage-factor endowments and differences in technology and thus it might be difficult to detect pollution-haven effects. Copeland and Taylor (2004) argue that the increase of pollution in developing countries might be caused by economic development rather than by dirty industry migration from overseas. Levinson and Taylor (2004) use imports instead of outward foreign direct investment (FDI) to measure the migration of firms. Their results indicate that the industries where abatement costs have increased most have seen the largest increases in net imports.

This paper provides an alternative explanation. In our view, pollution-intensive industries are generally characterized by imperfect competition, increasing returns to scale and large transportation costs, for instance, petroleum \& gas, chemicals, steel and other metals, pulp, automobile making, airlines, etc. Moreover, a proportionally larger share of such industries are located in the developed countries. Therefore, in this paper we investi-

\footnotetext{
${ }^{1}$ Copeland and Taylor (2004) distinguish between the pollution haven effect and the pollution haven hypothesis, the former of which refers to the effect of environmental policies on the migration of dirty firms, while the latter of which is related to the effect of a reduction in trade barriers on the migration of such firms. We shall investigate both, and as will soon become clear, these correspond to the impacts of respectively $t$ and $\phi$ in our model.

${ }^{2}$ See, for instance, Pethig (1976), Markusen et al. (1993), Chichilnisky (1994), Antweiler, Copeland and Taylor (2001), and Copeland and Taylor (2004).

${ }^{3}$ See, Walter (1982), Levinson (1996), List and Co (2000), Keller and Levinson (2002), Eskeland and Harrison (2003), and survey papers by Jaffe et al. (1995), Repetto (1995), and Xing and Kolstad (1996).
} 
gate a world of two countries, called the North N and the South S, each with a continuum of manufacturing industries under monopolistic competition and increasing returns. Manufacturing generates cross-border pollution which reduces agricultural production. The government in each country adopts a pollution abatement policy that requires firms to clean up their pollution by employing more workers. Firms can freely move across country borders, but not workers.

The model first enables us to clearly extract an income-reduction effect of pollution, even if two countries are completely symmetric. It arises from our cross-sectoral assumption that manufacturing pollution reduces agricultural production, which in turn decreases the local wage if pollution affects the emitting country more heavily than the other country. This results in a lower national income and a lower demand for manufacturing goods. We show that this income-reduction effect discourages firms to move to the country with laxer environmental regulations.

A second related effect is what we call the cost-reduction effect in manufacturing production, stemming from laxer environmental regulation, which requires firms to spend less labor on pollution abatement, and thus results in a lower manufacturing cost and generates more pollution. This is the mechanism that leads to the so-called pollution haven in the received literature.

In our model, the above two effects work in opposite directions and jointly determine the total effects of pollution. They can partly explain the empirical findings of Eskeland and Harrison (2003) that there exists some pollution-haven effect in industries with air pollution but not in industries with water pollution. According to our model, this arises because air pollution is more global which hurts both countries to more or less the same degree, and therefore the income-reduction effect is small. In contrast, water pollution is more local and the corresponding income-reduction effect is large enough to obscure the cost-reduction effect.

We further find that under asymmetry in country sizes, the manufacturing agglomeration force in the larger country $\mathrm{N}$, stemming from imperfect competition and increasing returns to scale, can alleviate the pollution-haven effect in the smaller country S, stemming from laxer environmental regulations. In other words, in models without incorporating 
the agglomeration force, the pollution haven effect may be exaggerated. For instance, the theoretical literature so far has overlooked these factors, and the hypothesis of pollution haven effects seemed so obvious. Our analysis demonstrates that if environmental regulation is slightly more stringent in $\mathrm{N}$ than in $\mathrm{S}$, then agglomeration forces can dominate the pollution effect and a pollution haven does not arise. This provides another explanation to why evidence of the pollution haven is hard to find.

The agglomeration force is strongly supported by a recent empirical study by Wagner and Timmins (2004), who test the pollution haven hypothesis using panel data of German FDI outflows in 6 manufacturing industries. They show that externalities associated with FDI agglomeration can bias estimates away from finding pollution haven effects. By including FDI stock to capture agglomeration effects, and controlling for possible correlation between unobservable attributes of FDI recipients and their environmental stringency, which had been ignored in previous analysis, they find strong support for the pollution haven hypothesis in the most pollution intensive industries such as chemicals and paper. They report that (p.22) “...(there exists) a spurious positive correlation between regulations and investment. It seems as if tough regulations attract pollution-intensive industries whereas in reality they relocate to a country because they benefit from FDI agglomeration." On the other hand, for some other industries such as primary metals, they find that the bias works in the opposite direction. This effect corresponds to the case when agglomeration forces are dominated by pollution effects in our model.

Perhaps the novel contribution of the present paper lies in that we integrate a model of economic geography with cross-border pollution. Specifically, manufacturing pollution is modeled as a bad that will decrease agricultural production. To the best of our knowledge, such cross-sectoral effects have not been analyzed in geography models yet. The known anti-agglomeration forces such as congestion directly reduce industrial instead of agricultural production in the literature. Modeling such cross-sectoral pollution in the foot-loose capital model enables us to discover the income-reduction effect, which reveals findings that are consistent with recent empirical studies. We also obtain clear-cut results in an analytically solvable manner, which is rare in models of spatial economics, considering the complexity of the present context. And finally, we show that as trade becomes freer, 
a "race to the bottom" of abatement policy may arise if countries choose their individual optimal policies noncooperatively. This calls for international cooperation, such as the Montreal Protocol and the Kyoto Protocol, especially in this age of globalization.

Our results also complement other findings in the literature. In contrast to the explanations in Grossman and Kruger (1993), Copeland and Taylor (2004) and Levinson and Taylor (2004), we demonstrate that even when two countries are completely identical (with neither comparative advantage no agglomeration forces) except the pollution abatement policy, the pollution haven effect can still be dominated due to the income-reduction effect of pollution. McAusland (2002) shows that capital owners have an incentive to cross-haul polluting factors across jurisdictions, because when capital generates pollution, those residents who are also capital owners consciously will invest their pollution-generating capital in a different jurisdiction in order to reduce pollution at home, whose mechanism is very different from ours. Pflüger (2001) studies ecological dumping under monopolistic competition, but countries are assumed to be symmetric, and the equilibrium analysis is limited to the cases of autarky and free trade.

This rest of the paper is organized as follows. Section 2 presents a brief setup of the model, describing the transboundary pollution and the increasing-returns-to-scale technology in industrial production. Section 3 describes the equilibrium. Section 4 demonstrates how the income-reduction effect and the cost-reduction effect work against each other and jointly determine the total pollution effect under symmetric countries. Section 5 analyzes the case of asymmetric countries in size and shows how the agglomeration force is related to the pollution effects. Section 6 looks into the optimal policies of the governments. We show that a race-to-the-bottom arises when transport costs are small, which calls for international coordination of environmental policies. Finally, we summarize our conclusions in Section 7.

\section{Brief Setup}

To character the manufacturing industry with imperfect competition, increasing returns, and transport costs, we employ the framework of spatial economics (see Krugman, 1980 
and Fujita et al., 1999). Specifically, we embed pollution into the standard "footloose capital (FC)" model (Martin and Rogers, 1995; Baldwin et al., 2003). The justification for using the FC model is that it allows the international mobility of capital but not labor, which serves our purpose of analyzing pollution problems between the North and the South, where there are far more barriers for the migration of labor than capital. This implies that a firm produces the same product after moving (Markusen (1995) documents that a majority of multinationals are horizontal in nature). More importantly, it is in line with the argument that capital used in the production of pollution-intensive goods yields a higher return in countries where firms bear lower costs of compliance with environmental regulations. Thus the pollution haven hypothesis says that dirty industries relocate to countries with lax environmental regulations.

There are two countries (the north $\mathrm{N}$ and the south $\mathrm{S}$ ), two sectors (manufacturing and agriculture), and two productive factors physical capital and labor, with capital being the internationally mobile factor and labor the immobile one. The name of "agriculture" here is not limited to pure agriculture, but represents any environmentally sensitive industry including fishing, forestry, bio-medicine, tourism, etc. Denote the amounts of capital and labor in country $\mathrm{N}$ as $K$ and $L$ respectively, and the counterparts in country $\mathrm{S}$ with an asterisk ${ }^{*}$. The worldwide endowments are fixed at $K^{w}$ and $L^{w}$. Manufacturing is characterized by increasing returns, monopolistic competition and iceberg trade costs, while the agricultural sector produces a homogeneous good under constant returns to scale and perfect competition with zero trade costs (free trade in agriculture).

The production cost of a typical manufacturing firm in the FC model consists of two parts: fixed cost and variable cost. To keep the model simple and tractable, we assume that the fixed cost involves only one unit of capital while the variable cost $l$ units of labor. In addition, firms must dispose their pollution according to the national environmental abatement policy. While many papers in the literature model this by an environmental tax, we assume that the manufacturing firms must employ additional workers for pollution abatement. Specifically, each manufacturing firm in country N must spend $t$ units of extra labor for waste disposal per unit of output and the counterpart in country $\mathrm{S}$ is $t^{*}$ units of labor. The total cost function for a firm in country $\mathrm{N}$ (resp. S) is therefore $r+(l+t) w x$ 
[resp. $\left.r^{*}+\left(l+t^{*}\right) w^{*} x\right]$, where $r\left(\operatorname{resp} . r^{*}\right)$ and $w\left(\right.$ resp. $\left.w^{*}\right)$ are the rewards to capital and labor in country $\mathrm{N}$ (resp. S) respectively, and $x$ is the firm-level output. The use of an abatement policy instead of a tax simplifies the model so that we do not need to consider how to spend the tax revenue.

As noted in Copeland and Taylor (1999, P. 138), ample empirical evidence links industrial pollution to reduced fishing and agricultural yields, to negative effects on the value of standing forests, and to beach closures that hurt tourism. The problem is further complicated by the fact that pollution is transboundary (such as carbon emissions), under which the amount of pollution is determined by the environmental policies of not one but both countries. Many studies usually adopt a specific function of transboundary pollution. For instance, Benarroch and Thille (2001) assume a linear production function in the agricultural sector. Here we assume a more general one, by denoting the agricultural production of a worker in country $\mathrm{N}$ by $\alpha\left(t, t^{*}\right)>0$, which is not necessarily linear. And the counterpart in country $\mathrm{S}$ is $\alpha^{*}\left(t, t^{*}\right)>0$. We can call them the agricultural productivity in $\mathrm{N}$ and $\mathrm{S}$ respectively. The productivity function is symmetric in the sense that $\alpha\left(t, t^{*}\right)=\alpha^{*}\left(t^{*}, t\right)$. In other words, there is no other first-nature difference between the two countries in agricultural production, except the effects of industrial pollution. Furthermore, we assume

$$
\begin{aligned}
& \alpha\left(t, t^{*}\right) \begin{cases}\geq \alpha^{*}\left(t, t^{*}\right) & \text { if } t>t^{*} \\
=\alpha^{*}\left(t, t^{*}\right) & \text { if } t=t^{*} \\
\leq \alpha^{*}\left(t, t^{*}\right) & \text { if } t<t^{*} .\end{cases} \\
& \frac{\partial \alpha}{\partial t}>0, \quad \frac{\partial \alpha}{\partial t^{*}}>0 .
\end{aligned}
$$

Relationship (1) indicates that agricultural production is considered to be higher in a country with more stringent environmental policy. Some types of pollution (e.g., water contamination and sulfur dioxide emission) impact local areas more heavily than far-away areas, so that the strict inequalities hold in (1). However, other types (e.g., carbon dioxide emission) are more global and impact local and far-away areas more or less the same, then $\alpha\left(t, t^{*}\right)=\alpha\left(t^{*}, t\right)$ holds even if $t \neq t^{*}$. In addition, (2) indicates that a better environment 
(less pollution or more stringent environmental policy) generates a higher agricultural production in both countries.

Denote the share of capital owned by country $\mathrm{N}$ as $\theta_{K}=K / K^{w}$, and the share of capital employed in country $\mathrm{N}$ as $\theta$, which is exactly $\mathrm{N}$ 's share of world industry: $\theta=n / n^{w}$, where notation $n^{w}$ denotes the mass (roughly speaking, the number) of industrial varieties available worldwide, and $n$ is the counterpart in $\mathrm{N}$ only. Note that we have adopted the standard assumption in the FC model that one firm uses only one unit of capital, and therefore, $n^{w}=K^{w}$.

In each country, each individual shares the same Cobb-Douglas tastes for the two types of goods:

$$
U=\frac{1}{\mu^{\mu}(1-\mu)^{1-\mu}} C_{M}^{\mu} C_{A}^{1-\mu}
$$

where $C_{M}$ represents a composite index of the consumption of $M$-sector goods, $C_{A}$ is the consumption of the $A$-sector good, and $\mu \in(0,1)$ is a constant representing the expenditure share of manufactured goods. The quantity index $C_{M}$ is a subutility function defined over a continuum of varieties of manufactured goods $C_{M}=\left(\int_{0}^{n^{w}} c_{i}^{1-\frac{1}{\sigma}} d i\right)^{\frac{\sigma}{\sigma-1}}$. Notation $c_{i}$ denotes the consumption of each available variety $i, \sigma>1$ is the constant elasticity of substitution between any two varieties and $1-1 / \sigma$ is the intensity of the preference for variety in manufactured goods.

Let $E$ be the total expenditure in country N. Then the indirect utility can be written as

$$
V=\frac{E}{P}, \quad P=p_{A}^{1-\mu}\left(\int_{0}^{n^{w}} p_{i}^{1-\sigma} d i\right)^{\frac{\mu}{1-\sigma}}
$$

where $P$ is called the price index, $p_{i}$ is the price of manufacturing variety $i$, and $p_{A}$ is that of $A$. Analogous definitions hold for Southern variables, all of which are denoted by an asterisk.

As in the standard literature of spatial economics, this paper assumes that the agricultural product is freely transported between two countries. Assuming that no country has enough labor to satisfy world demand for $A$, then the prices of the agricultural good in two countries are the same: $p_{A}=p_{A}^{*}$. We use agriculture as the numéraire good such that $p_{A}=p_{A}^{*}=1$. In the manufacturing sector, we assume Samuelson's iceberg form of 
interregional transportation costs: $\tau>1$ units of the manufactured good must be shipped for one unit to reach the other region.

Physical capital moves in search of the highest nominal reward. Following established tradition in economic geography, we assume that markets for goods adjust instantaneously, while interregional migration of capitals is relatively slow, implying that wages adjust much faster than the capital share. Also following the literature, we apply a standard dynamic system to describe the international factor flows:

$$
\dot{\theta}=\left(r-r^{*}\right)(1-\theta) \theta
$$

This is adopted from replicator dynamics, routinely used in evolutionary game theory (Weibull, 1995, p. 73), and is also used in standard textbooks such as Fujita et al. (1999, p. 62) and Baldwin et al. (2003, p. 72). Intuitively, capital moves to country $\mathrm{N}$ if $r>r^{*}$, in proportion to the present shares $\theta$ in country $\mathrm{N}$ and $1-\theta$ in country $\mathrm{S}$.

\section{Equilibrium}

Utility maximization yields the demand function for $A$ as $C_{A}=(1-\mu) E / p_{A}$, where $E$ is the expenditure in country N. Perfect competition in the $A$ sector forces marginal cost pricing, adjusted by agricultural productivity: $p_{A}=w / \alpha\left(t, t^{*}\right), p_{A}^{*}=w^{*} / \alpha^{*}\left(t, t^{*}\right)$. Since $p_{A}=p_{A}^{*}=1$, we have $w=\alpha\left(t, t^{*}\right)=w^{*}=\alpha^{*}\left(t, t^{*}\right)$. Therefore, the wage in the country with a better environment is higher if transboundary pollution affects the local country more severely, while wages in both countries are the same if transboundary pollution is symmetrically global.

Because of the transport costs, the prices of the manufacturing goods in the two countries are different. Let $p_{i}$ be the price of product $i$ in country $\mathrm{N}$ made in country $\mathrm{N}$, $p_{i}^{*}$ be the price of product $i$ in country $\mathrm{S}$ made in country $\mathrm{S}, \bar{p}_{i}$ be the price of a product $i$ in country $\mathrm{N}$ made in country $\mathrm{S}$ and $\bar{p}_{i}^{*}$ be the price of a product $i$ in country $\mathrm{S}$ made in country N. Then Dixit-Stiglitz monopolistic competition implies

$$
p_{i}=\frac{w(l+t) \sigma}{\sigma-1}, \quad p_{i}^{*}=\frac{w^{*}\left(l+t^{*}\right) \sigma}{\sigma-1}, \quad \bar{p}_{i}=\frac{\tau w^{*}\left(l+t^{*}\right) \sigma}{\sigma-1}, \quad \bar{p}_{i}^{*}=\frac{\tau w(l+t) \sigma}{\sigma-1} .
$$


Country N's consumption of product $j$ manufactured in country $\mathrm{N}$ is

$$
c_{j}=\frac{p_{j}^{-\sigma} \mu E}{\int_{0}^{\theta K^{w}}\left(p_{i}\right)^{1-\sigma} d i+\int_{0}^{\theta^{*} K^{w}}\left(\bar{p}_{i}\right)^{1-\sigma} d i}
$$

and country S's consumption of this variety is

$$
\bar{c}_{j}^{*}=\frac{\left(\bar{p}_{j}^{*}\right)^{-\sigma} \mu E^{*}}{\int_{0}^{\theta K^{w}}\left(\bar{p}_{i}^{*}\right)^{1-\sigma} d i+\int_{0}^{\theta^{*} K^{w}}\left(p_{i}^{*}\right)^{1-\sigma} d i},
$$

where the expenditures are calculated as $E=r K+w L$ and $E^{*}=r^{*} K^{*}+w^{*} L^{*}$.

Let

$$
\delta \equiv\left[\frac{w^{*}}{w} \frac{l+t^{*}}{l+t}\right]^{\sigma-1}=\left[\frac{\alpha^{*}\left(t, t^{*}\right)}{\alpha\left(t, t^{*}\right)} \frac{l+t^{*}}{l+t}\right]^{\sigma-1},
$$

which represents the trade-off between the impacts of pollution on the industrial and agricultural productions. The following lemma shows that $\delta$ summarizes the impact of pollution policies in the two countries and, therefore, it is called the South-North policy burden ratio subsequently. Intuitively, if country $\mathrm{N}$ imposes a higher $t$ for a cleaner environment, manufacturing in this country must consume more labor and becomes more costly. And as a benefit of a better environment, the agricultural sector becomes more productive and Northern workers enjoy a higher wage. This results in $\delta<1$.

Lemma 1 The following holds

$$
\delta \begin{cases}<1 & \text { if } t>t^{*} \\ =1 & \text { if } t=t^{*} \\ >1 & \text { if } t<t^{*}\end{cases}
$$

Proof: Straightforward from (1) and the fact that $\sigma>1$.

Note that the higher wage in country $\mathrm{N}$ leads to a higher national income, which in turn creates a larger consumption market for goods than country S. Therefore, a more stringent environmental policy does not necessarily imply that firms will be driven out of the country, which we shall investigate in detail soon. 
Under Dixit-Stiglitz competition, if firms are located in both countries, then the operating profit of a manufacturing firm in $\mathrm{N}$ is

$$
\begin{aligned}
r & =\frac{p_{j}^{1-\sigma} \mu \theta_{E} E^{w}}{\sigma\left[p_{i}^{1-\sigma} \theta K^{w}+\phi\left(p_{i}^{*}\right)^{1-\sigma}(1-\theta) K^{w}\right]}+\frac{\phi\left(p_{j}\right)^{1-\sigma} \mu \theta_{E}^{*} E^{w}}{\sigma\left[\phi p_{i}^{1-\sigma} \theta K^{w}+\left(p_{i}^{*}\right)^{1-\sigma}(1-\theta) K^{w}\right]} \\
& =\frac{b E^{W}}{K^{w}}\left[\frac{\theta_{E}}{\theta+\frac{\phi}{\delta}(1-\theta)}+\frac{\phi \theta_{E}^{*}}{\phi \theta+\frac{1-\theta}{\delta}}\right] \\
& =\frac{b B E^{w}}{K^{w}}
\end{aligned}
$$

where

$$
\begin{aligned}
& b=\frac{\mu}{\sigma}, \quad B=\frac{\theta_{E}}{\Delta}+\phi \frac{\theta_{E}^{*}}{\Delta^{*}}, \\
& \theta_{E}=\frac{E}{E^{w}}, \quad \theta_{E}^{*}=\frac{E^{*}}{E^{w}}, \quad \phi=\tau^{1-\sigma} \in(0,1), \\
& \Delta=\theta+\frac{\phi(1-\theta)}{\delta}, \quad \Delta^{*}=\phi \theta+\frac{1-\theta}{\delta} .
\end{aligned}
$$

Notation $\phi$ decreases with the transport $\operatorname{cost} \tau$ and also measures the freeness of trade. To simplify notation, we use it to substitute for $\tau$ subsequently. Similarly, the operating profit of a manufacturing firm in $\mathrm{S}$ is

$$
r^{*}=\frac{b B^{*} E^{w}}{\delta K^{w}}
$$

where

$$
B^{*}=\phi \frac{\theta_{E}}{\Delta}+\frac{\theta_{E}^{*}}{\Delta^{*}}
$$

Note that with Cobb-Douglas preferences, total worldwide spending on manufacturing equals $\mu E^{w}$, and the total operating profits of all firms are simply $\mu E^{w} / \sigma=b E^{w}$ (as a result from (5) and (6), $B=B^{*} / \delta=1$ ). Meanwhile, the definition of $E^{w}$ gives $E^{w}=$ $w \theta_{L} L^{w}+w^{*}\left(1-\theta_{L}\right) L^{w}+b E^{w}$, so we have

$$
E^{w}=\left[w \theta_{L}+w^{*}\left(1-\theta_{L}\right)\right] \frac{L^{w}}{1-b}
$$

Under the assumption that $\theta_{K}$ of the capital in each country belongs to Northern 
capital owners regardless of the industry distribution ratio $\theta$, then the average reward to capital is the same in the two countries, regardless of the spatial allocation of industry and the degree of openness. Therefore, $E=w \theta_{L} L^{w}+b \theta_{K} E^{w}$ holds and we obtain

$$
\theta_{E}=\frac{w}{\theta_{L} w+\left(1-\theta_{L}\right) w^{*}}(1-b) \theta_{L}+b \theta_{K}, \quad \theta_{L}=\frac{L}{L^{w}}, \quad \theta_{K}=\frac{K}{K^{w}}
$$

In the long-run equilibrium, $r=r^{*}$ holds for $0<\theta<1$, which yields

$$
\theta=\frac{\theta_{E}}{1-\delta \phi}-\frac{\phi\left(1-\theta_{E}\right)}{\delta-\phi} \equiv \theta_{0}
$$

If $\theta_{0} \notin(0,1)$, then we obtain a corner equilibrium. Specifically, if $\delta \geq 1 / \phi$, then $B>B^{*} / \delta$ and $r>r^{*}$ holds from (5) and (6), which results in a corner equilibrium $\theta=1$. Similarly, if $\delta<\phi$, then $\theta=0$ is a corner equilibrium. In summary, the equilibrium is generally written as

$$
\theta= \begin{cases}1, & \text { if } \delta \geq \frac{1}{\phi} \\ 0, & \text { if } \delta \leq \phi \\ \max \left\{0, \min \left\{1, \theta_{0}\right\}\right\}, & \text { if } \phi<\delta<\frac{1}{\phi}\end{cases}
$$

In the following, we implicitly assume that $\delta \in(\phi, 1 / \phi)$ when we discuss $\theta_{0}$.

\section{Symmetric Countries and Income-Reduction Ef- fects}

Grossman and Kruger (1993) state that the direction of trade in dirty goods is primarily determined by conventional determinants of comparative advantage. For instance, a country's comparative advantage may lie in the production of "dirty" goods, and thus it is difficult to extract evidence of a pure pollution haven. In contrast, in the present paper we wish to show that even in the absence of comparative advantage, a pollution haven may not arise. To do this, we rule out comparative advantage á la Heckscher-Ohlin, by assuming $\theta_{L}=\theta_{K}=\Theta$ in the subsequent analysis.

Furthermore, this section considers the benchmark of completely symmetric countries 
(i.e., $\Theta=1 / 2$ ), except that $\mathrm{N}$ is more stringent in pollution abatement policy. Note that in the original footloose capital model with Dixit-Stiglitz monopolistic competition, no agglomeration force is observed when two countries are completely identical. We show instead that an income-reduction effect of cross-sectoral pollution might be strong enough to dominate a cost-reduction effect of pollution, and as a result a pollution haven does not arise. The only condition we need is that pollution affects the emitting country more severely than the other country.

We proceed as follows. Since $\theta_{K}=\theta_{L}=1 / 2$, the expenditure ratio $\theta_{E}$ of (8) can be written as $\theta_{E}=\left[(2-b) w+b w^{*}\right] /\left[2\left(w+w^{*}\right)\right]$. Substituting it into (9), we obtain the industry distribution ratio

$$
\theta_{0}=\frac{1}{2}-\theta_{C}+\theta_{I}
$$

where

$$
\theta_{C} \equiv \frac{\phi\left(1-\delta^{2}\right)}{2(\delta-\phi)(1-\delta \phi)}, \quad \theta_{I} \equiv \frac{w-w^{*}}{w+w^{*}} \frac{(1-b) \delta\left(1-\phi^{2}\right)}{2(\delta-\phi)(1-\delta \phi)} .
$$

Recall as in (10), $\theta_{0}$ is the candidate of an interior equilibrium. Therefore, it also characterizes the location of firms as $\theta$ does. In (11), the first term on the RHS, 1/2, comes from the symmetry between the two countries. The second term, $-\theta_{C}$, represents the cost-reduction effect in manufacturing production that firms are likely to locate in the country with cheaper labor, stemming from a laxer pollution abatement policy. In fact, $-\theta_{C}$ increases with $\delta$. This term is negative if country $\mathrm{N}$ is more stringent (i.e., $\delta<1$ ) and positive if country $\mathrm{N}$ is laxer in pollution abatement. The third term, $\theta_{I}$, is the incomereduction effect, showing that firms seek to locate in the country with a higher purchasing power. It arises because manufacturing pollution reduces agricultural production, and in turn lowers the local wage if pollution affects the emitting more severely than the foreign country. To be specific, when $t>t^{*}$ we have $w=\alpha\left(t, t^{*}\right)>w^{*}=\alpha^{*}\left(t, t^{*}\right)$. Then the local demand in country $\mathrm{S}$ is smaller because of the lower wage. In other words, although the production cost for a firm locate in country $\mathrm{S}$ is lowered due to the laxer environmental policy, the firm bears a higher transport cost for its products to be shipped to the $\mathrm{N}$ market to be consumed, which has a higher purchasing power due to its higher income arising from higher agricultural productivity (less pollution). This effect is also caused by 
the difference in abatement policy.

Note that simultaneously demonstrating the cost-reduction effect and the incomereduction effect and that they work against each other are novel contributions of the present paper. In the received literature, only the former effect has been analyzed. Studies such as Pflüger (2001) also use the monopolistic competition model, but with logarithm in the utility function instead, and the income-reduction effect cannot be seen. Thus the received literature straightforwardly generates the so-called pollution haven, but not cases of a reverse pollution haven which we shall discuss shortly.

One might argue that developing countries attract FDI because wages there are low. As more FDI comes in, wages increase. This is true without counting the negative effects of pollution. If such externalities in other environmentally sensitive sectors are included as in the present model, then the increase in income will be discounted. South Korea during its high-growth period (1960s and 1970s), used to dump industrial waste along its rivers, especially the Han river. Recently the government decided to spend huge budgets to clean them up and introduced comprehensive water management measures. A couple of acts were enacted in 1999 and 2000 for the Han river, the Nakdong river, the Geum river and the Yeongsan river (Republic of Korea: World Health Organization, 2004). Also, many argue that the recent rapid growth of the Chinese economy comes at the expense of future resources, whose negative impact can only be more fully understood 20 or 30 years later.

Let us continue with more discussion of the cost-reduction effect and the incomereduction effect, which are both related to the difference of pollution policies. In particular, when the two countries adopt the same pollution abatement policy $t=t^{*}$, the policy burden ratio becomes $\delta=1$. Then both the cost-reduction effect and the incomereduction effect disappear. In this special case, there is only one equilibrium $\theta=1 / 2$, which is stable for arbitrary $\phi$ under dynamic system (4). This simplest case obscures some important features so that the trade pattern variations do not show up.

However, the cost-reduction effect is independent of the agricultural production which the income-reduction effect depends on. To see this, we now consider the case that industrial pollution on the agricultural sector is globally symmetric so that $\alpha\left(t, t^{*}\right)=$ $\alpha^{*}\left(t, t^{*}\right)$. In this case, $w=w^{*}$ holds, and hence the income-reduction effect disappears. 
If country $\mathrm{N}$ is more stringent in environmental regulation, then $t>t^{*}$ and the costreduction effect $-\theta_{C}$ is negative. Seeking for a lower production cost, more firms move to locate in S. According to (10), the equilibrium in this case is described as follows.

$$
\theta \begin{cases}1, & \text { if } \frac{1+\phi^{2}}{2 \phi} \leq \delta \\ \in\left(\frac{1}{2}, 1\right), & \text { if } 1<\delta<\frac{1+\phi^{2}}{2 \phi} \\ =1 / 2, & \text { if } \delta=1 \\ \in\left(0, \frac{1}{2}\right), & \text { if } \frac{2 \phi}{1+\phi^{2}}<\delta<1 \\ 0, & \text { if } \delta \leq \frac{2 \phi}{1+\phi^{2}}\end{cases}
$$

Dynamic system studies (e.g., Tabuchi and Zeng 2004) show that an interior equilibrium of (4) is stable iff $d\left(r-r^{*}\right) / d \theta$ is negative at the equilibrium. Using this stability condition, we know that (11) is stable when $2 \phi /\left(1+\phi^{2}\right)<\delta<\left(1+\phi^{2}\right) /(2 \phi)$. On the contrary, for small $\delta$ such that $\delta<2 \phi /\left(1+\phi^{2}\right)$, we have $B<B^{*} / \delta$ at $\theta=0$ so the corner equilibrium $\theta=0$ is stable. Similarly, for large $\delta$ such that $\delta>\left(1+\phi^{2}\right) /(2 \phi)$, the corner equilibrium $\theta=1$ is stable. Meanwhile, (12) shows that more firms locate in $\mathrm{S}$ (i.e., $\theta<1 / 2)$ if country $\mathrm{S}$ has laxer environmental regulations. This special case confirms the pollution haven hypothesis in the literature.

More generally, one expects $\alpha\left(t, t^{*}\right) \neq \alpha^{*}\left(t, t^{*}\right)$ because pollution might affect local agriculture more severely. Specifically, $\alpha\left(t, t^{*}\right)>\alpha^{*}\left(t, t^{*}\right)$ so that $w>w^{*}$ if $t>t^{*}$. Then the income-reduction effect arises, and if it dominates the cost-reduction effect, a pollution haven may not arise. Also, it is straightforward to check that both $\theta_{C}$ and $\theta_{I}$ are increasing with $\phi$ when $\delta<1$. However, since the two effects are opposite in sign, the whole pollution effect is not a monotone function of $\phi$. The net pollution effect is observed only if the cost-reduction effect dominates the income-reduction effect. For example, if consumers prefer more manufacturing goods ( $\mu$ is large), and/or the elasticity of substitution $\sigma$ between varieties is small, and/or pollution is very local, then $\theta_{I}$ is small so that it is dominated by $\theta_{C}$. Otherwise, $\theta_{I}$ is large, and we can observe a reverse pollution haven effect. 
These results can partially explain the empirical findings of Eskeland and Harrison (2003, p. 13), who report that for more global pollution such as air pollution, there is a significantly positive association between pollution and the pattern of FDI in several countries, even after controlling for other factors. According to our model, this arises because the income effect disappears, and hence the pollution effect can be more easily picked up by empirical studies. But for more local pollution such as water pollution or toxicity, the income effect still remains, working against the pollution effect. And hence the pattern might be found to be reversed: FDI is less likely in sectors where emissions are higher.

The above results are obtained under neither comparative advantage nor agglomeration forces, since the two countries are assumed to be completely identical except in pollution abatement policy. Summarizing these results, we can establish:

Proposition 1 Under the conditions of completely symmetric countries and globally asymmetric pollution in the sense that pollution affects the emitting country more severely than the other country, the "pollution haven" effect is the compound of the cost-reduction effect and the income-reduction effect. The former encourages firms to locate in the pollution haven but the latter discourages them. As a consequence, a pollution haven arises only if the former dominates the latter. Otherwise a reverse pollution haven may arise.

\section{Asymmetric Countries and the Home Market Ef- fect}

Now we are ready to tackle the asymmetric case of $\Theta \neq 1 / 2$, i.e., countries are different in size. Without loss of generality, we assume that $\mathrm{N}$ is larger than S, i.e., $\Theta>1 / 2$. Our purpose is to demonstrate that the pollution haven effect can be dominated by other forces even when pollution is globally symmetric in the sense that pollution affects all countries the same, near or far. In this case the income-reduction effect derived in the previous section disappears, but we show that agglomeration forces work against and can dominate the cost-reduction effect. 
We continue to rule out comparative advantage by setting $\theta_{L}=\theta_{K}=\Theta$. Then the firm ratio (9) becomes

$$
\begin{aligned}
\theta_{0}= & \Theta+\frac{\phi\left(1-2 \phi \delta+\delta^{2}\right)(2 \Theta-1)}{2(\delta-\phi)(1-\delta \phi)}-\frac{\phi\left(1-\delta^{2}\right)}{2(\delta-\phi)(1-\delta \phi)} \\
& +\frac{\left(w-w^{*}\right) \Theta(1-\Theta)}{w \Theta+w^{*}(1-\Theta)} \frac{(1-b) \delta\left(1-\phi^{2}\right)}{(\delta-\phi)(1-\delta \phi)}
\end{aligned}
$$

If the two countries adopt the same environmental policy $t=t^{*}$, then $\delta=1$ and (13) is simplified as

$$
\theta_{01} \equiv \Theta+\frac{2 \phi}{1-\phi}\left(\Theta-\frac{1}{2}\right)
$$

Obviously $\theta_{01}>\Theta$, which says that the country with relatively larger local demand (country $\mathrm{N}$ ) attracts a more-than-proportionate share of firms in the monopolistically competitive manufacturing industry. This is called the home market effect (HME) in the literature of spatial economics (Krugman, 1980). Davis and Weinstein (1999) interprete the HME as a magnified impact of a high demand for production and find some evidence of it. Notice that the HME originates from increasing-returns-to-scale technologies in manufacturing. It is different from the scale effect in the literature of environmental economics (e.g., Grossman and Krueger (1993), Copeland and Taylor (2004)), which is the increase in pollution generated if the whole economy were simply scaled up using a framework of constant-returns-to-scale technologies.

Differentiation gives

$$
\frac{\partial \theta_{01}}{\partial \phi}=\frac{2 \Theta-1}{(1-\phi)^{2}}>0
$$

which implies that the Northern relative market size matters more when trade barriers are lower. This is called the secondary magnification effect in spatial economics, e.g., Head and Mayer (2004).

When $\delta \neq 1$, the HME is accompanied by the pollution effect, which is represented by the third and forth terms of (13) on the RHS. To examine how various effects are combined, we first consider the case of globally symmetric pollution so that $w=w^{*}$. Then 
the income-reduction effect disappears and (13) becomes

$$
\theta_{02} \equiv \Theta+\theta_{\mathrm{HME}}-\theta_{C}
$$

where

$$
\theta_{\mathrm{HME}}=\frac{\phi\left(1-2 \phi \delta+\delta^{2}\right)(2 \Theta-1)}{2(\delta-\phi)(1-\delta \phi)} \text { and } \theta_{C}=\frac{\phi\left(1-\delta^{2}\right)}{2(\delta-\phi)(1-\delta \phi)} .
$$

In the above, expression $\theta_{\mathrm{HME}}$ represents the $\mathrm{HME}$ and $\theta_{C}$ is the cost-reduction effect of pollution.

Note that $\theta_{\mathrm{HME}}$ is positive while $-\theta_{C}$ is negative iff $\delta<1$ (i.e., $t>t^{*}$ : the larger country $\mathrm{N}$ holds a more stringent environmental policy). Furthermore, $\theta_{\mathrm{HME}}$ decreases with $\delta$ if $\delta<1$ and $\theta_{C}$ always decreases with $\delta$ :

$$
\begin{aligned}
& \frac{\partial \theta_{\mathrm{HME}}}{\partial \delta}=-\frac{\left(1-\delta^{2}\right)(2 \Theta-1) \phi\left(1-\phi^{2}\right)}{2(\delta-\phi)^{2}(1-\delta \phi)^{2}}<0, \text { iff } \delta<1 \\
& \frac{\partial \theta_{C}}{\partial \delta}=-\frac{\phi\left[(1-\delta \phi)^{2}+(\delta-\phi)^{2}\right]}{2(\delta-\phi)^{2}(1-\delta \phi)^{2}}<0 .
\end{aligned}
$$

Evidently, $\theta_{02}$ is an interior equilibrium (i.e., $\left.\theta_{02} \in(0,1)\right)$ iff

$$
\delta \in\left(\frac{1}{\frac{\Theta}{\phi}+(1-\Theta) \phi}, \frac{1-\Theta}{\phi}+\Theta \phi\right)
$$

which is a subinterval of $(\phi, 1 / \phi)$. Furthermore, condition (17) ensures stability of the interior equilibrium under dynamic system (4). Corner equilibrium $\theta=1$ is stable for a larger $\delta$ outside of (17), and corner equilibrium $\theta=0$ is stable for a smaller $\delta$.

We can make the following statement to synthesize the HME and the pollution effect.

Proposition 2 If pollution is globally symmetric, then for any $\phi \in(0,1), \theta_{02}$ increases with $\delta$ of (17), and there exists a critical $\delta^{\sharp} \in(\phi, 1)$, such that the equilibrium distribution is

$$
\theta \begin{cases}>\Theta & \text { if } \delta>\delta^{\sharp}, \\ =\Theta & \text { if } \delta=\delta^{\sharp}, \\ <\Theta & \text { if } \delta<\delta^{\sharp} .\end{cases}
$$


Proof: The derivative of $\theta_{02}$ with respect to $\delta$ is

$$
\frac{\partial \theta_{02}}{\partial \delta}=\frac{\phi\left[(1-\delta \phi)^{2}-\left(1-\delta^{2}\right)\left(1-\phi^{2}\right) \Theta\right]}{(\delta-\phi)^{2}(1-\delta \phi)^{2}} \geq \frac{\phi(\delta-\phi)^{2}}{(\delta-\phi)^{2}(1-\delta \phi)^{2}} \geq 0
$$

where the first inequality holds evidently if $\delta \geq 1$ and is also true if $\delta<1$ because $\Theta \leq 1$. Therefore, $\theta_{02}$ increases with $\delta$.

Given the above monotonic relationship, from (15) we also obtain

$$
\theta_{\mathrm{HME}}-\theta_{C}=\frac{\phi}{2(\delta-\phi)(1-\delta \phi)}\left[\Theta \delta^{2}-\phi(2 \Theta-1) \delta+\Theta-1\right]
$$

The expression in square brackets is a quadratic function of $\delta$. It is negative at $\delta=\phi$ and positive at $\delta=1$. Thus there exists a unique solution (denoted by $\delta^{\sharp}$ ) satisfying

$$
\Theta \delta^{2}-\phi(2 \Theta-1) \delta+\Theta-1=0
$$

in $(\phi, 1)$. Proposition 2 immediately follows from (10) and (15).

We can use Figure 1 below to explain Proposition 2 in detail, which can be divided into 3 cases.

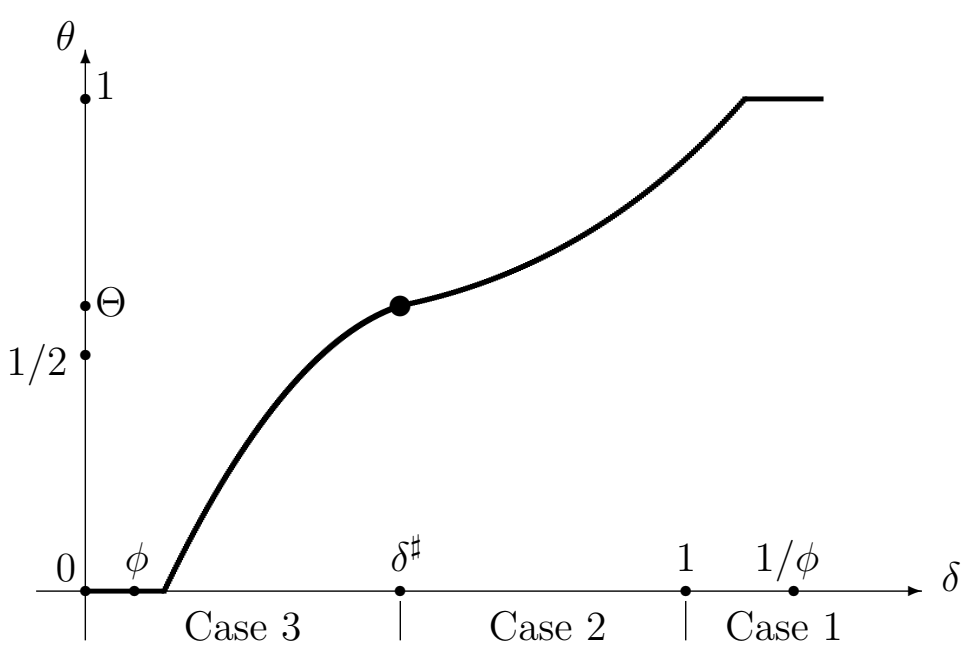

Figure 1: The Location of Manufacturing Firms w.r.t. $\delta$

Case 1: If country $\mathrm{N}$ has laxer environmental regulations than country $\mathrm{S}\left(t<t^{*}\right)$, then 
$\delta>1\left(>\delta^{\sharp}\right)$. The home market effect and the cost-reduction effect enhance each other. As a result, the share of manufacturing firms located in country $\mathrm{N}, \theta$, is much higher than N's share of factor endowments $\Theta$.

According to Taylor (2004), the pollution haven hypothesis also indicates that a movement from autarky to free trade would lead to the relocation of dirty production from country $\mathrm{N}$ to country $\mathrm{S}$ if $t^{*}<t$. We obtain the same result here, but with a little difference. To see this, note that $t^{*}<t$ leads to $\delta<1$. Since interval (17) converges to one point, 1, when $\phi$ approaches $1, \delta$ is in the left of interval (17). Therefore, all firms move to country $\mathrm{S}$ in the unique stable equilibrium when the transport $\operatorname{cost} \tau$ is very small. The difference from the existing literature is, our research suggests that one reason we might not observe the pollution haven effect from the empirical data is because the transport cost in the real world is not free at all, as in case 1 of Figure 1.

Case 2: If country $\mathrm{S}$ has a slightly laxer regulation than $\mathrm{N}$, i.e., $t>t^{*}$ but that $\delta^{\sharp}<\delta<1$, then the HME and the cost-reduction effects work in opposite directions but the former dominates the latter. In other words, a more than proportionate share of firms still agglomerates in country $\mathrm{N}$ despite that country $\mathrm{S}$ would be a pollution haven without counting the agglomeration forces. This provides another explanation why the pollution haven effect is difficult to pick up in empirical studies. As mentioned in the introduction, our theoretical results are supported by the empirical study of Wagner and Timmins (2004), who include FDI stock to capture agglomeration effects in their analysis. They conclude that it would seem that tough regulations attract pollution-intensive industries whereas in reality they relocate to a country because they benefit from FDI agglomeration, which is consistent with case 2 in Figure 1.

Further, the analytical solvability of the present model allows us to say more. For example, we find that the critical value $\delta^{\sharp}$ of (18) increases with $\phi$ and decreases with $\Theta$ because

$$
\frac{\partial \delta^{\sharp}}{\partial \phi}=\frac{(2 \Theta-1) \delta^{\sharp}+1-\Theta}{2 \Theta\left(\delta^{\sharp}-\frac{2 \Theta-1}{2 \Theta} \phi\right)}>0,
$$




$$
\frac{\partial \delta^{\sharp}}{\partial \Theta}=-\frac{\left(\delta^{\sharp}-\phi\right)^{2}+\phi(1-\phi)}{2 \Theta\left(\delta^{\sharp}-\frac{2 \Theta-1}{2 \Theta} \phi\right)}<0 .
$$

Therefore, case 2 is more likely to arise when transport costs are high and/or when countries are more different in size.

Case 3: Finally, if country $\mathrm{S}$ has much laxer environmental regulations than $\mathrm{N}$ such that $\delta<\delta^{\sharp}$, then the cost-reduction effect dominates the HME. In other words, a more than proportionate share of firms locate in country $\mathrm{S}$ in order to escape from the more stringent environmental regulations in country N. This corresponds to the industries with small agglomeration forces such as primary metals in the study of Wagner and Timmins (2004). Researchers in spatial economics find that often it is hard to pick up the HME in empirical studies (e.g., Davis and Weinstein, 1999 and 2003), and they even term the phenomenon "reverse HME" (e.g., Yu, 2005). The present model clearly shows that the HME exists, but we provide an explanation from a different angle - the cost-reduction effect of pollution, which can dominate the HME.

Now we turn to examine how industrial location changes with decreasing transport costs (i.e., increasing $\phi$ ), given the policy burden ratio $\delta$. For simplicity, we keep the assumption of globally symmetric pollution and focus on the case of $\theta>1 / 2$ and $\delta<1$ (the larger country $\mathrm{N}$ holds a more stringent regulation policy).

The equilibrium expression (10) is rewritten as

$$
\theta= \begin{cases}0 & \text { if } \phi \geq \delta \\ \max \left\{0, \min \left\{1, \theta_{02}\right\}\right\} & \text { if } \phi<\delta\end{cases}
$$

where $\theta_{02}$ is defined in (15). It includes two cases. (i). When the trasport costs are small $(\phi \geq \delta)$, the cost-reduction effect dominates so that country S attracts all firms; (ii). For larger transport costs $(\phi<\delta), \theta_{02}$ is not a monotone function of $\phi$. In this case, similar to (14), the HME is increasing in $\phi$ :

$$
\frac{\partial \theta_{\mathrm{HME}}}{\partial \phi}=\frac{\delta(2 \Theta-1)\left[(1-\delta \phi)^{2}+(\delta-\phi)^{2}\right]}{2(\delta-\phi)^{2}(1-\delta \phi)^{2}}>0
$$


i.e., the HME is stronger for smaller transport costs. However, it is complicated by the cost-reduction effect. In fact, from (15) we derive

$$
\frac{\partial \theta_{02}}{\delta \partial \phi}=\frac{\Theta\left[(1-\delta \phi)^{2}+(\phi-\delta)^{2}\right]-(1-\delta \phi)^{2}}{(\delta-\phi)^{2}(1-\delta \phi)^{2}}
$$

The first term of the numerator on the RHS is positive while the second term is negative. If the pollution policies are very different such that $\delta \leq \sqrt{(1-\Theta) / \Theta}$, then $\partial \theta_{02} / \partial \phi$ is always negative so that the equilibrium ratio $\theta$ strictly decreases from $\Theta$ to 0 with decreasing transport $\operatorname{costs} \tau$. The situation is plotted on the left panel of Figure 2. On the other hand, if the pollution policies are not too much different so that $\delta>\sqrt{(1-\Theta) / \Theta}$, then $\theta_{02}$ increases with $\phi$ until

$$
\phi^{\sharp} \equiv \frac{\sqrt{\Theta} \delta-\sqrt{1-\Theta}}{\sqrt{\Theta}-\sqrt{1-\Theta} \delta},
$$

and then decreases to 0 after $\phi^{\sharp}$. The situation is plotted on the right panel of Figure 2 . Therefore, we can conclude with

Proposition 3 The Northern relative market size matters less when the environmental policy in country $S$ is sufficiently lax, and freer trade is more likely to cause a pollution haven to arise.
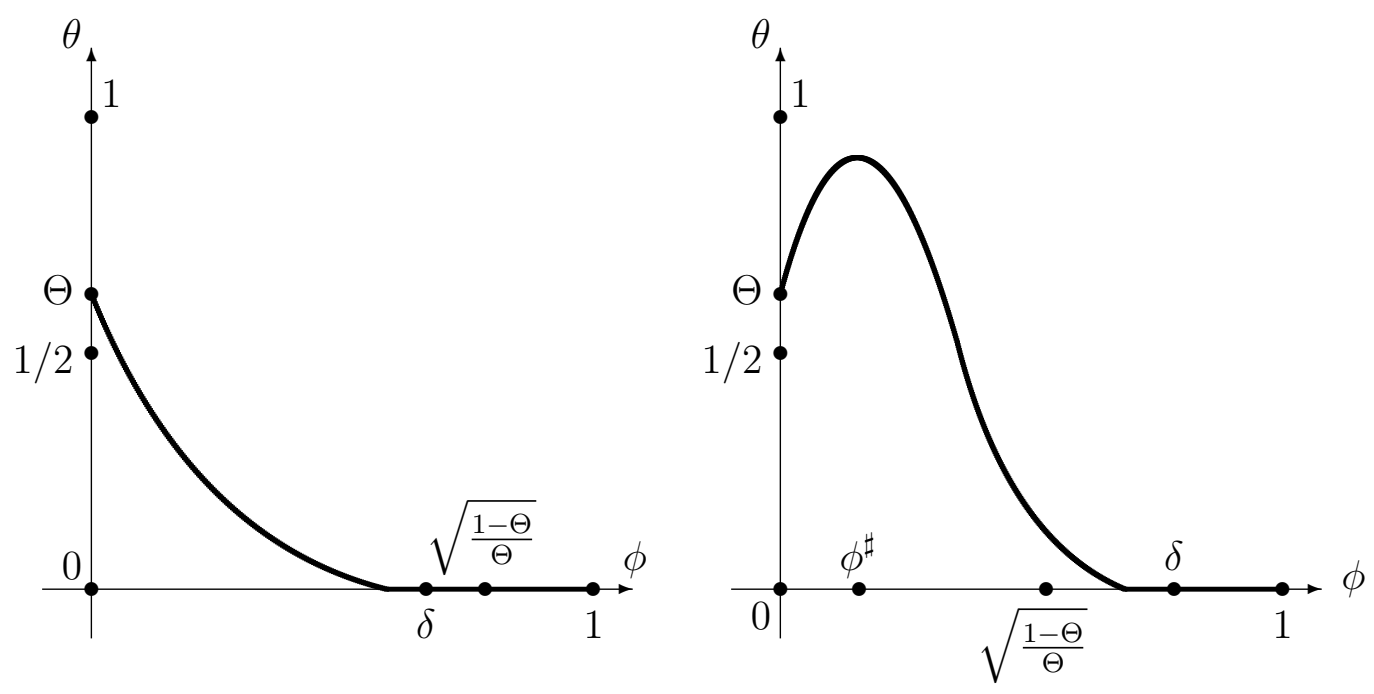

Figure 2: The Location of Manufacturing Firms w.r.t. $\phi$ 
Having explained Proposition 3, now we are ready to examine the most general situation in which manufacturing pollution impacts agricultural production in the emitting country more heavily than that in the foreign country. Due to pollution, the benefit of more industrial firms is accompanied by the loss of lower agriculture production and lower wages. That is, $\alpha\left(t, t^{*}\right)>\alpha^{*}\left(t, t^{*}\right), w>w^{*}$ and $\delta<1$ hold if $t>t^{*}$. We already know that this leads to a small local demand for the manufacturing good, and a firm in S must pay transport costs to sell in the larger $\mathrm{N}$ market, i.e., the income-reduction effect. Precisely, (13) can be re written as

$$
\begin{aligned}
\theta_{0} & =\Theta+\theta_{\mathrm{HME}}-\theta_{C}+\theta_{I} \\
\text { where, } \quad \theta_{I} & =\frac{\left(w-w^{*}\right) \Theta(1-\Theta)}{w \Theta+w^{*}(1-\Theta)} \frac{(1-b) \delta\left(1-\phi^{2}\right)}{(\delta-\phi)(1-\delta \phi)} \text {. }
\end{aligned}
$$

Since $\theta_{I}$ decreases with $\Theta$, the income-reduction effect is the largest in the case of symmetric countries. Meanwhile, since $\delta /[(\delta-\phi)(1-\delta \phi)]$ decreases with $\delta$ iff $\delta<1, \theta_{I}$ is larger for a smaller $\delta$. And since $\theta_{C}$ and $\theta_{I}$ have opposite signs, we know that the larger the difference between $\alpha\left(t, t^{*}\right)$ and $\alpha^{*}\left(t, t^{*}\right)$, the more the pollution effect is weakened by $\theta_{I}$. However, because of (16), the sign of the whole pollution effect is determined by the relative size of parameters $b, \Theta$, among others.

Overall, for $\delta<1$ and $\Theta>1 / 2$, the HME and the income-reduction effect combined can alleviate the cost-reduction effect in $\mathrm{S}$, which makes it more difficult to observe the pollution effect in S empirically.

We are in a position to summarize the main conclusions of this section:

Proposition 4 Under the conditions of asymmetric country sizes without comparative advantage, there are three effects jointly determining the industrial location. The costreduction effect of pollution encourages the firms to locate in the country with laxer regulation, the income effect discourages it, and simultaneously firms prefer the larger country due to the home market effect.

This Proposition implies that in industries characterized by imperfect competition and increasing returns to scale, a pollution haven may not arise in the smaller developing 
country with laxer environmental regulations, either because the agglomeration forces in the larger developed country dominates the pollution haven effect, and/or because the income-reduction effect of pollution dominates the cost-reduction effect.

\section{The Need for International Policy Coordination}

We have examined the industrial location given each country's environmental policy in the previous sections. Now we turn to the decision making of each governments and examine the issue of a "race to the bottom" in abatement policy. We demonstrate that without international policy cooperation, if countries were to choose their individual abatement policies optimally but noncooperatively, then as trade costs decrease, a "race to the bottom" arises. On the other hand, with international coordination, it can be avoided. To illustrate our point, we only need to focus on the case of completely symmetric countries: $\Theta=1 / 2$. Furthermore, our argument is concentrated on the case that the two policies are not too different so that $\theta_{0}$ of (9) is indeed an interior equilibrium.

Using (3), (7), (8) and (9), the welfare in $\mathrm{N}$ can be written as

$$
\begin{aligned}
V_{N} & =\frac{E}{P}=\theta_{E} E^{w}\left(K^{w}\right)^{\frac{\mu}{\sigma-1}}[\theta \delta+(1-\theta) \phi]^{\frac{\mu}{\sigma-1}}\left[\frac{\sigma-1}{w^{*}\left(l+t^{*}\right) \sigma}\right]^{\mu} \\
& =\left[\theta_{0} \delta+\left(1-\theta_{0}\right) \phi\right]^{\frac{\mu}{\sigma-1}} \frac{(2-b) w+b w^{*}}{4(1-b)}\left[\frac{\sigma-1}{w^{*}\left(l+t^{*}\right) \sigma}\right]^{\mu} L^{w}\left(K^{w}\right)^{\frac{\mu}{\sigma-1}} \\
& =\Gamma \times W\left(t, t^{*}\right),
\end{aligned}
$$

where

$$
\Gamma=\frac{L^{w}\left(K^{w}\right)^{\frac{\mu}{\sigma-1}}\left(1-\phi^{2}\right)^{\frac{\mu}{\sigma-1}}}{2^{2+\frac{\mu}{\sigma-1}}(1-b)}\left(\frac{\sigma-1}{\sigma}\right)^{\mu}
$$

is a positive constant and independent of the abatement policies $t$ and $t^{*}$, and

$$
W\left(t, t^{*}\right)=\frac{\left[(2-b) w+b w^{*}\right]^{1+\frac{\mu}{\sigma-1}}}{\left\{[w(l+t)]^{\sigma-1}-\phi\left[w^{*}\left(l+t^{*}\right)\right]^{\sigma-1}\right\}^{\frac{\mu}{\sigma-1}}\left(w+w^{*}\right)^{\frac{\mu}{\sigma-1}}} .
$$

Now consider a noncooperative game between the two governments of $\mathrm{N}$ and S. Each government maximizes its own welfare choosing own abatement policy, simultaneously. 
In other words, given $t^{*}$, the government of country $\mathrm{N}$ maximizes $W$ by choosing $t$. The first order condition for the optimal $t$ is

$$
\begin{aligned}
\frac{\partial W}{\partial t}= & W\left\{\left(1+\frac{\mu}{\sigma-1}\right) \frac{(2-b) \frac{\partial w}{\partial t}+b \frac{\partial w^{*}}{\partial t}}{(2-b) w+b w^{*}}-\frac{\mu}{\sigma-1} \frac{\frac{\partial w}{\partial t}+\frac{\partial w^{*}}{\partial t}}{w+w^{*}}\right. \\
& \left.-\mu \frac{\left.[w(l+t)]^{\sigma-2}\right]\left[\frac{\partial w}{\partial t}(l+t)+w\right]-\phi\left[w^{*}\left(l+t^{*}\right)\right]^{\sigma-2}\left[\frac{\partial w^{*}}{\partial t}\left(l+t^{*}\right)\right]}{[w(l+t)]^{\sigma-1}-\phi\left[w^{*}\left(l+t^{*}\right)\right]^{\sigma-1}}\right\} \\
= & 0 .
\end{aligned}
$$

Analogously, the Southern government maximizes $W^{*}\left(t^{*}, t\right)$ which can be defined symmetrically as $W\left(t, t^{*}\right)$. And its first order condition can be derived similarly as above.

Solving the two equations, given that the two countries are completely identical, we must obtain $t=t^{*} \equiv t^{e}$, where $t^{e}$ is the noncooperative pollution abatement policy that solves

$$
\begin{aligned}
\frac{\partial \alpha\left(t^{e}, t^{e}\right)}{\partial t}[ & {\left[1-\frac{b}{2}+\frac{(1-b) \mu}{2(\sigma-1)}-\frac{\mu}{1-\phi}\right]+\frac{\partial \alpha^{*}\left(t^{e}, t^{e}\right)}{\partial t}\left[\frac{b}{2}-\frac{(1-b) \mu}{2(\sigma-1)}+\frac{\phi \mu}{1-\phi}\right] } \\
= & \frac{\mu \alpha\left(t^{e}, t^{e}\right)}{(1-\phi)\left(l+t^{e}\right)} .
\end{aligned}
$$

In particular, if pollution is globally symmetrical, then the above equation is simplified as

$$
\frac{1}{\alpha\left(t^{e}, t^{e}\right)} \frac{\partial \alpha\left(t^{e}, t^{e}\right)}{\partial t}=\frac{\mu}{(1-\phi)(1-\mu)\left(l+t^{e}\right)} .
$$

The RHS converges to infinity if $\phi$ approaches 1 . Therefore, as a solution of (19), $t^{e}$ becomes very small, implying a very low noncooperative abatement. This gives rise to the so-called a "race to the bottom" of environmental policy.

Notice that this phenomenon is related to Proposition 3, in which we showed that as trade becomes freer, a pollution haven is more likely to arise. Basically there is a trade-off involving the optimal regulation policy $t$. We know that on the one hand, the incomereduction effect of a laxer regulation decreases the local nominal wage; on the other hand, a laxer regulation attracts more firms due to the cost-reduction effect. The latter effect lowers the local price index by increasing the number of manufacturing varieties. This decrease in the price index in turn raises the real wages of its residents. As trade cost falls, 
each country will then try to attract more firms into its boundary by choosing a lower abatement, the only policy considered here. Note that this result is obtained without taking into account the negative impacts of pollution on consumer utility. Depending on how severe such negative externalities are, if they are also considered, then this result may change.

In order to avoid the "race to the bottom", we now consider the optimal environmental policy if there is a worldwide planner who can specify $t=t^{*}=t^{o}$. Summing up the welfare of the two countries yields

$$
\begin{aligned}
V_{N}+V_{S}= & \frac{E}{P}+\frac{E^{*}}{P^{*}} \\
= & \left(K^{w}\right)^{\frac{\mu}{\sigma-1}}\left(1-\phi^{2}\right)^{\frac{\mu}{\sigma-1}}\left(\frac{\sigma-1}{\sigma}\right)^{\mu} \\
& \frac{E^{w}}{p_{A}^{1-\mu}[w(l+t)]^{\mu}}\left[\frac{\theta_{E}^{1+\frac{\mu}{\sigma-1}}}{(1-\delta \phi)^{\frac{\mu}{\sigma-1}}}+\frac{\left(1-\theta_{E}\right)^{1+\frac{\mu}{\sigma-1}}}{(\delta-\phi)^{\frac{\mu}{\sigma-1}}}\right],
\end{aligned}
$$

where $\theta_{E}$ is determined by (8).

Setting $t=t^{*}=t^{o}$, we have

$$
w=w^{*}, \quad \delta=1, \quad \theta_{E}=\frac{1}{2}, \quad E^{w}=\frac{w L^{2}}{1-b} .
$$

Then the total welfare is simplified as

$$
V_{N}+V_{S}=\frac{w^{1-\mu}}{p_{A}^{1-\mu}(l+t)^{\mu}} \times \text { Constant }=\frac{[\alpha(t, t)]^{1-\mu}}{(l+t)^{\mu}} \times \text { Constant }
$$

Therefore, optimal policy $t^{o}$ is the solution to:

$$
\frac{1}{\alpha\left(t^{o}, t^{o}\right)} \frac{d \alpha\left(t^{o}, t^{o}\right)}{d t^{o}}=\frac{\mu}{(1-\mu)\left(l+t^{o}\right)}
$$

Different from (19), expression (20) is independent of $\phi$. This implies that even when trade is completely free, the worldwide planner would not choose zero abatement. Therefore, when transport costs decrease (especially in the age of globalization), international cooperation such as the Montreal Protocol and the Kyoto Protocol is called for to prevent 
a "race to the bottom" in environmental standards. And the call becomes stronger with decreasing trade costs.

\section{Conclusion}

The pollution haven hypothesis, that a tightening up of pollution regulation will have an effect on firm location, has strong support from theory but little from empirics. To explain for this gap, some authors conclude that the location of industries is conventionally determined by comparative advantage of factor endowments and differences in technology, instead of the pollution policies.

While comparative advantage is evidently one factor, it is not the unique one. Recognizing that manufacturing production usually involves technologies of increasing returns to scale and imperfect competition, we constructed a model demonstrating that the agglomeration force of industries is a potential reason for firms not to locate in the "pollution haven". Incorporating cross-sectoral and transboundary pollution into the footloose capital model of spatial economics, we indeed find three effects besides the usual explanation of comparative advantage. While the cost-reduction effect encourages polluting firms to move to the country with lax regulations, the income-reduction effect discourages such a move. In addition, the agglomeration force of the home market effect hinders firms from moving out of the larger developed country. These results are supported by recent empirical findings.

To keep the model tractable, we have abstracted from incorporating the negative impacts of pollution in the consumer utility function and the national welfare function. Such effects work in the same direction as the income-reduction effect of pollution. Thus, taking into consideration such negative externalities makes it more difficult to find a pollution haven. 


\section{References}

Antweiler, W., B. Copeland and M. S. Taylor (2001), Is free trade good for the environment? American Economic Review 91, 877-908.

Baldwin R., R. Forslid, P. Martin, G. Ottaviano and F. Robert-Nicoud (2003), Economic Geography and Public Policy. Princeton University Press.

Benarroch, M. and H. Thille (2001), Transboundary pollution and the gains from trade, Journal of International Economics 55, 139-59.

Chichilnisky, G. (1994), Global environment and north-south trade, American Economic Review 84, 851-74.

Copeland, B.R. and M.S. Taylor (1999), Trade, spatial separation, and the environment, Journal of International Economics 47, 137-68

Copeland, B.R. and M.S. Taylor (2004), Trade, growth and the environment, Journal of Economic Literature 42, 7-71.

Davis, D.R. and D. Weinstein (1999), Economic geography and regional production structure: an empirical investigation, European Economic Review 43, 397-407.

@Davis, D.R. and D. Weinstein (2003), Market access, economic geography, and comparative advantage: an empirical assessment, Journal of International Economics 59, 1-23. @

Eskeland, G. and A. Harrison (2003), Moving to greener pastures? multinationals and the pollution haven hypothesis, Journal of Development Economics 70, 1-23.

Fujita M., P. Krugman and A.J. Venables, 1999. The Spatial Economy: Cities Regions and International Trade, The MIT Press.

Grossman, G.M. and A.B. Krueger (1993), Environmental Impacts of the North American Free Trade Agreement, in Mexico-U.S. Free Trade Agreement. Peter M. Garber, ed. Cambridge, MA: MIT Press, 13-56.

Head, K. and T. Mayer (2004), The empirics of agglomeration and trade, in J.V. Henderson and J.-F. Thisse, eds., Handbook of Regional and Urban Economics (volume 4). Amsterdam: Elsevier, 2609-2669. 
Jaffe, A.B., S.R. Peterson, P.R. Portney and R.N. Stavins (1995), Environmental regulation and the competitiveness of U.S. manufacturing: what does the evidence tell us? Journal of Economic Literature 33, 132-63.

Keller, W. and A. Levinson (2002), Environmental compliance costs and foreign Direct investment inflows to U.S. states, Review of Economics and Statistics 84, 691-703.

Krugman, P.R. (1980). Scale economics, product differentiation, and the pattern of trade, American Economic Review 70, 950-959.

Levinson, A. (1996), Environmental regulations and manufacturers' location choices: evidence from the census of manufactures, Journal of Public Economics 62, 5-29.

Levinson, A. and S. Taylor (2004), Unmasking the pollution effect, NBER working paper 10629.

List, J.A. and C.Y. Co (2000), The effects of environmental regulations on foreign direct investment, Journal of Environmental Economics and Management 40, 1-20.

Markusen, J.R. (1995), The boundaries of multinational enterprises and the theory of international trade, Journal of Economic Perspective 9 (2), 169-89.

Markusen, J.R., E.R. Morey and N.D. Olewiler (1993), Environmental policy when market structure and plant locations are endogenous, Journal of Environmental Economics and Management 24, 69-86.

Martin, P. and C.A. Rogers (1995), Industrial location and public infrastructure. Journal of International Economics 39, 335-351.

McAusland, C. (2002), Cross-Hauling of polluting factors, Journal of Environmental Economics and Management 44, 448-70.

Pethig, R. (1976), Pollution, welfare and environmental policy in the theory of comparative advantage, Journal of Environmental Economics and Management 2, 160-60.

Pflüger, M. (2001). Ecological dumping under monopolistic competition, Scandinavian Journal of Economics 103, 689-706.

Repetto, R. (1995), Jobs, Competitiveness and Environmental Regulation: What Are the Real Issues? World Resources Institute Research Report, Washington D.C. 
Republic of Korea, World Health Organization (2004), Environmental Health Country Profile.

Tabuchi, T. and D.-Z. Zeng (2004), Stability of spatial equilibrium, Journal of Regional Science 44, 641-660.

Taylor, M.S., 2004. Unbundling the pollution haven hypothesis. Advances in Economic Analysis and Policy 4(2), Article 8.

Wagner, U.J. and C. Timmins (2004), Agglomeration effects in foreign direct investment and the "Pollution Havens" Hypothesis, Working paper, Department of Economics, Yale University.

Walter, I. (1982), Environmentally induced industrial relocation to developing countries, in J. Rubin and T R. Graham, eds., Environment and Trade, New Jersey: Allanheld, Ossun, and Company.

Weibull, J.W. (1995), Evolutionary Game Theory, MIT Press.

Xing, Y. and C.D. Kolstad (1996), Environment and trade: a review of theory and issues. Working paper.

Yu, Z. (2005). Trade, market size, and industrial structure: revisiting the home market effect, Canadian Journal of Economics 38, 255-272. 